\title{
Does pre-dispersal seed predation limit reproduction and population growth in the alpine clonal plant Geum reptans?
}

\author{
Tina Weppler · Jürg Stöcklin
}

Received: 14 January 2005/ Accepted: 13 March 2006/Published online: 12 April 2006

(C) Springer Science+Business Media, Inc. 2006

\begin{abstract}
We studied the impact of the seed damaging gall midge larva Geomyia alpina on its perennial alpine host plant Geum reptans. We analysed the effect of seed predation on reproduction by seeds, i.e. seed number, seed mass, and seed viability and on growth and clonal propagation of non-protected plants in comparison to plants protected from predation by an insecticide. Additionally, we assessed the consequences of seed predation for population growth using matrix projection modelling. Seed predation resulted in a decrease in total seed mass per flower head by $23.8 \%$ in non-protected plants $(P<0.05)$. Individual seed mass decreased with increasing infestation intensity $(P<0.05)$. Seed number remained unaffected because the sucking feeding behaviour by gall midge larvae does not evoke seed abortion. Percent germination of seeds from non-protected plants was reduced by 97.9\% compared to seeds from protected plants. According to reduced seed viability, modelling revealed a decrease in population growth rate from $\lambda=1.055$ to $\lambda=1.041$. Predation did neither influence total plant biomass nor biomass fractions. But stolon dry-weight of non-protected plants increased by $24.1 \%(P<0.05)$, which may
\end{abstract}

T. Weppler $(\bowtie) \cdot$ J. Stöcklin Institute of Botany, University of Basel, Schönbeinstrasse 6, CH-4056 Basel, Switzerland e-mail: Tina.Weppler@unibas.ch indicate a trade-off between sexual reproduction and clonal propagation. Our results demonstrate that despite substantial reduction of viable seeds, predation by gall midge larvae only slightly affected population growth of $G$. reptans suggesting that in this alpine species, persistence by longevity and clonal propagation can balance potential seed losses by predation, at least for local population growth.

Keywords Clonal growth · Gall midge · Geomyia alpina $\cdot$ Herbivory $\cdot$ Matrix projection modelling

\section{Introduction}

Pre-dispersal seed predation is well known to have substantial impact on the relative reproductive success of individuals by limiting the number of viable seeds (e.g. Hendrix 1979; Louda 1982; Louda and Potvin 1995; Briese 2000; Leimu et al. 2002) and altering flowering phenology (e.g. Janzen 1971; Eriksson 1995; Louda and Potvin 1995; Albrectsen 2000; Mahoro 2002; Russell and Louda 2004). Predation of seeds prior to dispersal is experienced by a variety of plant species in different habitats throughout the world. Most pre-dispersal seed predation is caused by small insects showing high host-specificity (Crawley 1992). These predators cause damage to a 
variable degree by attacking whole fruits, feeding on individual seeds, or sucking on tissue of ovules (Crawley 1997). Theoretically, it is expected that pre-dispersal seed predation should have consequences not only for individual reproduction but also for growth and dynamics of populations if seed supply reduces recruitment to below the sustainable density (Harper 1977). Louda (1982) and Louda and Potvin (1995) were among the first who demonstrated a direct effect of inflorescencefeeding herbivores on recruitment, plant demography, and fitness by limiting total seed output. However, even despite an increasing number of studies associating seed predation and population growth (e.g. Briese 2000; Kelly and Dyer 2002; Fröborg and Eriksson 2003), effects of predispersal seed predation on population dynamics of most host-plants are still poorly understood and controversially discussed.

In fact, the persistence of many plant populations does not always depend critically upon current seed production (Cohen 1968; Eriksson 1996). Differences in life-histories largely determine how strong a plant may respond to seed losses or not. The existence of a persistent seed bank may buffer potential seed losses by seed consumers in time (Parker 1985; Crawley 1990). Also a species' life-span, particularly whether it is semelparous or iteroparous, is considered to be an important aspect in assessing the role of predispersal seed predation for population dynamics (Briese 2000). Immigration of seeds from other patches may balance low seed availability in predated populations (Roff 1974; Eriksson 1996). Nevertheless, since seed production of most plants is large, increasing mortality of seeds during germination can have substantial effects on the number of surviving seedlings in a population (Crawley 1992).

Most studies of the effects of pre-dispersal seed predation on recruitment and population growth focus on annual plants (e.g. Szentesi and Jermy 2003) or short-lived perennials (e.g. Louda and Potvin 1995; Briese 2000). In long-lived perennials, due to the complexity of recruitment, the impacts of seed losses are difficult to determine (Andersen 1989). Clearly, independent of lifehistory, species must be followed over several years and locations to account for environmental variation. A combination of field measurements and matrix projection modelling may provide a promising approach to assess the impact of seed predators on population growth rate (Fröborg and Eriksson 2003).

Destruction of flowers or immature fruits may induce changes in resource allocation of plants (Hendrix 1988). Compensation for seed losses might particularly evolve in plants subjected to a predictable risk of damage by host-specific herbivores (Crawley 1983; Järemo et al. 1996). As a consequence, resources that would have been used for seed and fruit maturation may be stored, may be allocated into compensatory flowers or fruits that would normally been aborted or may be used for the production of non-reproductive tissue (Janzen 1971; Hendrix 1979; Crawley 1997). Accordingly, for clonal plants it could be inferred that the loss of seeds due to predation may alter the balance between sexual reproduction and clonal growth in favour of the latter. Support for this assumption comes from studies detecting a trade-off between sexual reproduction and clonal propagation (e.g. Law et al. 1983; Sutherland and Vickery 1988; Piquot et al. 1998; Ronsheim and Bever 2000). However, interestingly, there are only few studies on seed predation in clonal plants considering potential benefits for clonal growth (Doak 1991).

We used an exclusion field experiment to determine the effects of pre-dispersal seed predation on sexual reproduction and clonal propagation in Geum reptans L., a long-lived alpine pioneer species occurring on glacier forelands. Furthermore, we simulated the consequences of reduced seed viability due to pre-dispersal seed predation on the population growth rate $(\lambda)$ of G. reptans using a matrix projection model. Geum reptans is an iteroparous rosette plant producing flower heads and above-ground stolons, but does not form a persistent seed bank. The seeds of this species are damaged by larvae of a recently discovered specialist gall midge (Skuhravá et al. 2006). We addressed the following questions: (1) What are the effects of pre-dispersal seed predation on reproduction by seeds, i.e. seed number, seed mass and seed viability? (2) Are other traits, i.e. growth and clonal propagation, also affected by the predation of the gall midge? (3) What are 
the consequences of pre-dispersal seed predation for population growth rate $(\lambda)$ ?

\section{Material and methods}

Study species

Geum reptans L. (Rosaceae) is a clonal perennial rosette plant occurring between 1950 and $3800 \mathrm{~m}$ a.s.l. This pioneer species grows on moist moraines and alluvial soils of glacier forelands, block fields and mountain ridges, particularly on lime-deficient soils. Its distribution ranges from the Central Alps to the Carpathians and the Mountains of Northern Albania and Macedonia (Weber 1995). Individuals of $G$. reptans are about $5-15 \mathrm{~cm}$ in height and form clumps of 1 to c. 7 leaf rosettes emerging from a taproot. In spring, axial leaf buds initiated in the previous year give rise to flower heads and c. 2 weeks later to above-ground stolons. Stolons can grow up to $1 \mathrm{~m}$ in length. At the end of a stolon, a clonal daughter rosette develops and establishes a new individual in autumn when the connection to the mother plant withers (clonal propagation). Flower heads are generally hermaphrodite and contain c. 100 ovaries, but male flower heads also rarely occur (Weber 1995; T. Weppler, unpubl.). Geum reptans is pollinated mainly by flies (Heß 2001); self-pollination of the proterogynous flower heads results in non-viable seeds (Rusterholz et al. 1993). Plants produce on average $105.9 \pm 11.0$ (mean $\pm \mathrm{SD}$ ) seeds per flower head; abortion of ovules is usually very low (0.6 $\pm 1.8 \%, n=60$; Authors, unpubl.). In accordance with the elongated hairy style, the nutlets are mainly wind-dispersed. Geum reptans forms no persistent seed bank (Schwienbacher and Erschbamer 2002).

Developing seeds of $G$. reptans are damaged by larvae of the recently described gall midge species Geomyia alpina Skuhravá (Cecidomyiidae; Skuhravá et al. 2006). We observed infestation by gall midge larvae in 10 out of 18 populations of G. reptans surveyed in the Swiss Alps (Fig. 1). Infestation of flower heads varied between $3.6 \%$ and $83.3 \%$. Geomyia alpina does not induce galls but feeding results in small and atrophied seeds sticking to each other (T. Weppler, unpubl.). Adult gall midges emerge in spring, mate and infest the flower heads of G. reptans by ovipositing eggs. Larvae hatch after several days and develop inside the flower heads sucking sap of developing nutlets. In autumn, the mature larvae leave the host plant and overwinter in the soil. Gall midges developing in alpine host plants show usually one generation per year
Fig. 1 Location of 18 populations of Geum reptans in Switzerland and their frequency of infestation (\%) by gall midge larvae. The filled part of pies refers to percent individuals with infested flower heads. Frequency of infestation was independent of altitude and successional stage of populations

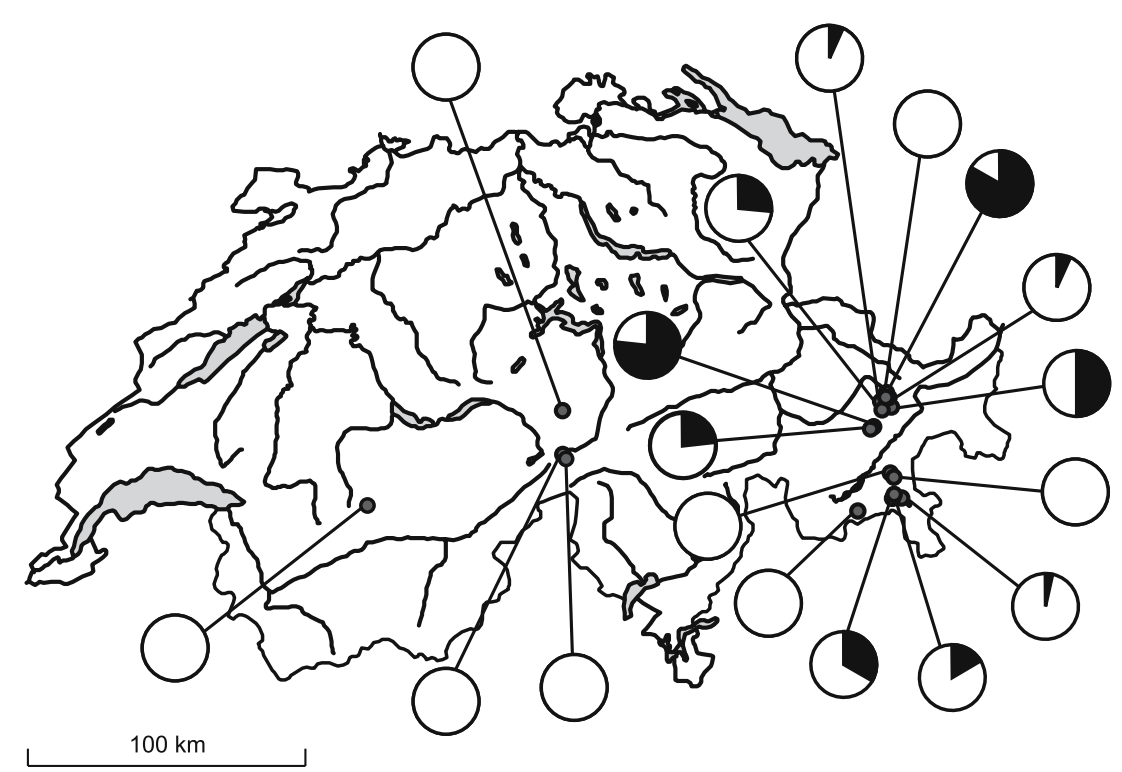


(Skuhravá et al. 1984), which is probably also true for the present species.

Study site

The study site is a large population of c. 20,000 individuals of Geum reptans on the foreland of Scaletta glacier in Eastern Switzerland (WNWexposed slope with c. $20^{\circ}$ inclination, $2400 \mathrm{~m}$ a.s.l., 791335/175478, Swiss national grid). In 1991, Rusterholz (1992) reported heavy infestation of this population by gall midge larvae, resulting in $10-40 \%$ seed loss. Gall midge larvae were again observed during 2000-2002 (no data available for 1992-1999), but we assume that gall midge larvae were continuously present since gall midge populations often remain at constant levels for prolonged periods (Skuhravá et al. 1984). No other predators feeding on seeds of G. reptans were observed.

Field study

At the end of June 2001, 122 individuals of Geum reptans with buds of flower heads were randomly selected so that the minimum distance between individuals was at least $2 \mathrm{~m}$ (Table 1). According to life-cycle stages of reproducing plants, individuals were grouped into three size classes: small (1 leaf rosette), medium (2-3 leaf rosettes), and large plants ( $\geq 4$ leaf rosettes). Twice the number of medium-sized plants was selected, because it was planned to harvest half of these plants in autumn 2001.

In half of the plants within each size class (64 plants in total), all flower heads were sprayed with a $0.05 \%$ solution of a systemic broad-spectrum insecticide against sucking and herbivorous insects (Perfekthion ${ }^{\circledR}$, BASF AG, Maag Agro, 8157 Dielsdorf, Switzerland; active ingredient dimethoat $(40 \%))$. Insecticide-treated plants are subsequently referred to as 'protected', regardless of whether they were infested. The flower heads of the other half of the plants (58 plants in total) were sprayed with the same amount of water; these plants are subsequently referred to as 'nonprotected'. The insecticide treatment was first applied on buds of flower heads and repeated fortnightly for 12 weeks. Direct treatment of unpollinated flower heads was avoided. We repeated the treatment on the same plants in 2002. However, due to high inter-annual variation in reproduction typical of $G$. reptans (Weppler et al. 2006) and an avalanche partly burying the study site, the number of experimental plants which flowered in the second year was very low. Thus, we mainly present results from 2001, and only a summary of the results from 2002 .

The number of stolons and flower heads per plant was counted fortnightly. From mid July to mid August, the intensity of larval infestation was measured fortnightly on a randomly selected flower head per plant and classified as (1) none (uninfested), (2) slightly (by 1-10 larvae infested), (3) heavily (by more than 10 larvae infested; mean larvae number of heaviest infested flower heads was 37.2). If the measures differed among surveys, the highest measured infestation intensity was chosen. Prior to seed-dispersal, all flower heads were bagged separately with small-meshed nylon fabric to avoid loss of mature seeds. At this time, new infestation of flower heads was unlikely. In October, mature seeds were harvested, air-dried, and the number of seeds, individual seed weight, and total seed weight per flower head was calculated. In October 2001,

Table 1 Number of flower heads and stolons per plant (mean \pm SE) in small, medium, and large individuals of Geum reptans in two treatments of an experiment to test for the effects of pre-dispersal seed predation by gall midge larvae

\begin{tabular}{lllll}
\hline Plant size & $N$ & Treatment & \# Flower heads per plant (mean \pm SE) & \# Stolons per plant (mean \pm SE) \\
\hline Small & 17 & Non-protected & $0.65 \pm 0.19$ & $1.47 \pm 0.44$ \\
Medium & 31 & Non-protected & $1.61 \pm 0.31$ & $1.13 \pm 0.24$ \\
Large & 10 & Non-protected & $2.50 \pm 0.73$ & $1.90 \pm 1.36$ \\
Small & 21 & Protected & $0.81 \pm 0.20$ & $0.52 \pm 0.15$ \\
Medium & 30 & Protected & $1.50 \pm 0.30$ & $1.07 \pm 0.23$ \\
Large & 13 & Protected & $3.08 \pm 0.89$ & $1.15 \pm 0.36$ \\
\hline
\end{tabular}

$N$ refers to the number of sampled individuals 
above-ground biomass of half of the mediumsized plants (15 non-protected, 14 protected) were harvested, separated into green leafs, dead leafs, stems, leaf buds, sexual and clonal reproductive organs. After drying at $80{ }^{\circ} \mathrm{C}$, the biomass was weighted.

In order to test whether growth of G. reptans was affected by the insecticide, 26 clonal offspring of untreated individuals were randomly selected in 2001 and raised in the greenhouse for 9 months. Thereafter, half of these plants were sprayed with insecticide and the other half was sprayed with the same amount of water ( 8 weeks; fortnightly applied). Above-ground biomass per plant was harvested, separated into the same fractions as in the field study and weighted after drying at $80^{\circ} \mathrm{C}$. The insecticide treatment did not have an effect on any of the collected biomass fractions or on total biomass $\left(F_{1,19}<1.4, P>0.05\right.$ for all biomass fractions and total biomass), confirming that the insecticide did not affect plant growth directly.

Seed viability and effect on population growth rate

To test for seed viability, mature seeds from 5 non-protected and 5 protected plants of Geum reptans were collected in 2001 and 2002. Additionally, mature seeds originating from a population at Lötschental not infested with gall midge larvae (SE-exposed slope with c. $24^{\circ}$ inclination, $2079 \mathrm{~m}$ a.s.1., 635850/144168, Swiss national grid, and $158 \mathrm{~km}$ apart from the foreland of Scaletta glacier) were collected in 2002. Seeds collected in 2001 and 2002 were stored at room temperature until spring 2003. After washing in $80 \%$ ethyl alcohol, seeds were placed into petri-dishes lined with filter paper ( 25 seeds per petri-dish), watered and chilled at $4{ }^{\circ} \mathrm{C}$ for 6 weeks. For the seeds from 2001, 10 petri-dishes per treatment were used, 15 petri-dishes per treatment were used for the seeds from 2002, and 10 petri-dishes were used for the seeds of the not infested population at Lötschental (in total 60 petri-dishes). Afterwards, petri-dishes were transferred into the greenhouse (mean temperature c. $20^{\circ} \mathrm{C}$ ) and seeds were allowed to germinate for 8 weeks. Germination was detected by penetration of the radicula, and germinated seeds were continually removed. Percent germination was calculated for each petri-dish. Percent germination within treatments did not differ between years (Wilcoxon-rank sum test; $Z=-0.19, P>0.8$ ) indicating that storage had no effects on seed viability.

To analyse the consequences of pre-dispersal seed predation on population growth rate of $G$. reptans, we used a stochastic matrix model based on demographic data from a nearby population not infested by the gall midge, situated at Vadret da Porchabella $(2650 \mathrm{~m}, 11 \mathrm{~km}$ distant from the study site). This specific model was developed to analyse population growth of G. reptans in relation to variation in proportions of sexual reproduction and clonal growth (Weppler et al. 2006). Here, for the computation of the population growth rate $\lambda$, a standard transition matrix was calculated based on demographic data over 3 years (2000-2002) from observations of 579 plants in 30 permanent plots of $1 \mathrm{~m}^{2}$ at Vadret da Porchabella. Calculations of population growth rates were performed with the program package Ramas EcoLab 2.0, Sinauer Associates, Inc. Transition probabilities were calculated between five life-cycle stages (seedlings, juveniles, small adults, medium adults, large adults). During the 3 years of observation at Vadret da Porchabella, sexual reproduction and clonal propagation occurred regularly. The numbers of seeds and stolons were counted separately for each stage of adult plants and averaged over the 3 years. Similarly, the percentages establishment of seedlings and stolons were observed yearly and averaged over the study period. An annual production of $69.8 \pm 22.7$ seeds (mean \pm SD) and $1.2 \pm 0.1$ stolons was found per reproducing adult; percentage germination was $1.2 \%$, and percentage of successful clonal propagation of rosettes at the end of stolons was $53.2 \%$. Population growth rate of this population not infested by the gall midge was $\lambda=1.055$ (Weppler et al. 2006). To simulate the effect of seed predation by the gall midge observed in the population at Scaletta glacier on population growth rate, the matrix model described above was modified to take into account the decreased number of viable seeds after predation. Mean calculated seed numbers derived from the population at 
Vadret da Porchabella were multiplied by the reduction in viable seeds due to infestation frequency observed in the field experiment at Scaletta glacier. The simulated decrease in population growth rate $\lambda$ was compared with the observed population growth rate in the population not infested by the gall midge and with the growth rate of the same population simulated without any viable seed production allowing only growth by clonal propagation $(\lambda=1.027)$. To evaluate the relative contribution of life-cycle components to population growth rate, elasticities of matrix elements were calculated using the program package $\mathrm{R} 2.1 .1$. The elasticity of $\lambda$ was highest to changes in survival of adult plants (elasticity $73.7 \%$ ). The elasticity of $\lambda$ to changes in growth was $8.8 \%$ and elasticities of $\lambda$ to changes in clonal growth and sexual reproduction were $11.6 \%$ and $0.08 \%$, respectively. Long-term effects of population growth were then evaluated with stochastic simulations over 30 years and 1000 replicates (Caswell 2001).

\section{Data analysis}

Individual plants were treated as replicates. Aborted flower heads and incomplete stolons were excluded except for the analysis of biomass. If more than one flower head or stolon was present in a plant, means for seed mass and seed number per flower head and stolon number were calculated. If necessary, data were logtransformed to achieve normally distributed residuals and variance homogeneity. KruskalWallis tests were used to compare differences in the number of flower heads and stolons per plant in total and for each size class and to examine the effect of treatment on percent germination. $T$-tests were performed to test for effects of treatment on plant biomass, stolon dry-weight, seed number per flower head, and total seed mass per flower head. The influence of infestation intensity on the number of seeds per flower head and on individual seed mass was analysed by one-way ANOVA. To study the effect of gall midge infestation on population growth, population growth rates $(\lambda)$ were calculated. All statistical analyses were conducted in JMP 4.0, SAS Institute Inc.

\section{Results}

Field experiment 2001

In $100 \%$ of the flower heads of non-protected plants, living larvae of Geomyia alpina occurred whereas only dead larvae were found in $78.6 \%$ of the protected plants, (with the rest, $21.4 \%$ free of larvae), data that confirm the effectiveness of the insecticide.

The number of flower heads and stolons did not differ between treatments. The number of flower heads significantly increased with increasing plant size (Kruskal-Wallis test; chisquare = 10.4 for protected and 9.8 for non-protected plants, $P<0.01$ ), but the number of stolons was not influenced by plant size (Kruskal-Wallis test; chisquare $=2.7, P=0.3$ for protected and chisquare $=0.7, P=0.7$ for non-protected plants; Table 1).

Predation by gall midge larvae did not affect the number of developing seeds per flower head $(85.3 \pm 3.2$ (mean $\pm \mathrm{SE})$ for protected and $85.0 \pm 3.6$ for non-protected plants; $F_{1,88}=0.02$, $P=0.9$ ). Seed number per flower head significantly increased with infestation intensity $(81.9 \pm 4.3$ and $93.1 \pm 3.9$ for slightly and heavily infested flower heads, respectively; $F_{2}, 87=3.5$, $P<0.05)$. In non-protected plants, total seed mass per flower head was significantly reduced by $23.8 \%$ compared to protected plants $\left(F_{1,88}=5.4\right.$, $P<0.05$; Fig. 2a), and individual seed mass of heavily infested flower heads was significantly lower compared to not infested flower heads $\left(F_{2,87}=5.0, P<0.01\right.$; Fig. $\left.2 b\right)$.

Total biomass of non-protected and protected plants did not differ $(2822.5 \pm 469.3 \mathrm{mg}$ for protected and $2462.4 \pm 390.3 \mathrm{mg}$ for non-protected plants; $\left.F_{1,27}=0.3, P=0.6\right)$. However, stolon dryweight of non-protected plants significantly increased by $24.1 \%\left(F_{1,17}=7.0, P<0.05\right.$; Fig. 3$)$ and stolon length increased by $13.6 \%\left(F_{1,17}=3.8\right.$, $P=0.07)$, but the latter was not significant.

Seed viability and effect on population growth rate

Percent germination of seeds from non-protected plants was significantly different from seeds from 

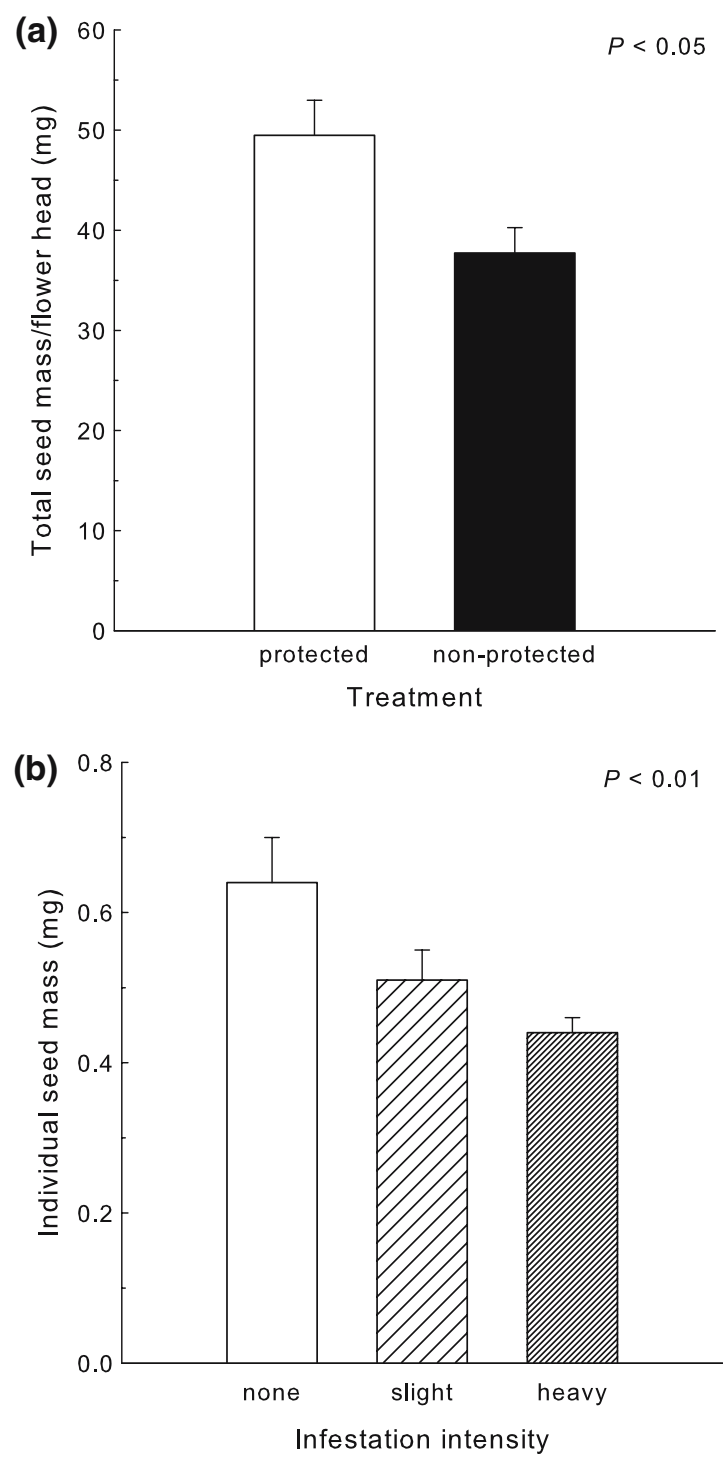

Fig. 2 (a) Effect of pre-dispersal seed predation by gall midge larvae on total seed mass per flower head (mean $\pm \mathrm{SE}$ ) of Geum reptans. (b) Influence of infestation intensity (heavy, slight, none) by gall midge larvae on individual seed mass (mean $\pm \mathrm{SE}$ ) of G. reptans

protected plants (it was reduced by $97.9 \%$ compared to seeds from protected plants; KruskalWallis test; chisquare $=15.3, P<0.001$; Fig. 4) while percent germination of seeds from protected plants did not differ (Kruskal-Wallis test; chisquare $=0.1, P=0.8$ ) when compared with seeds originated from an uninfested population. Simulated population growth rate of Geum reptans decreased from $\lambda=1.055$ to $\lambda=1.041$ when viable seed number was reduced according to the

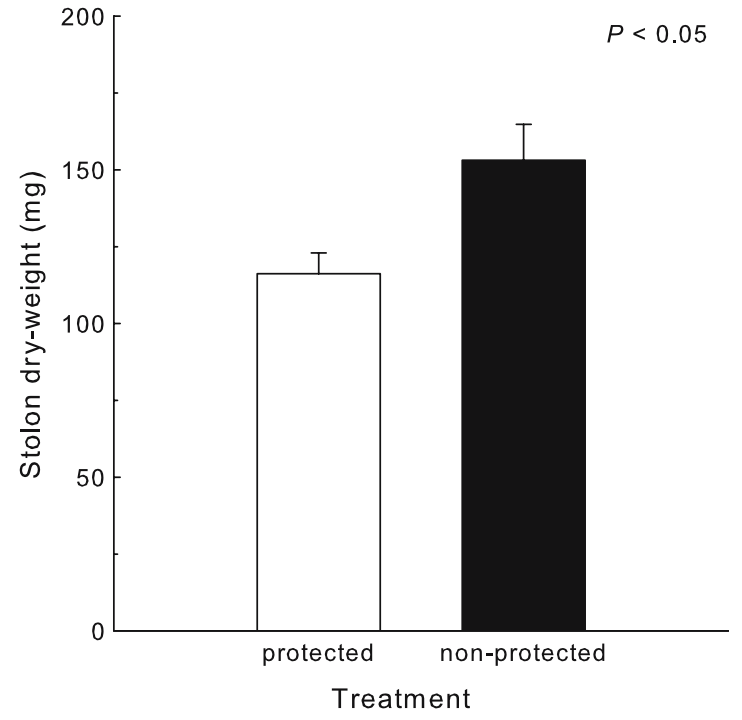

Fig. 3 Effect of pre-dispersal seed predation by gall midge larvae on stolon dry-weight (mean $\pm \mathrm{SE}$ ) of Geum reptans $(n=29)$

observed seed loss due to predation. This would result in a decrease of the predicted population size by $38.1 \%$ after 30 years.

\section{Results from 2002}

In the second year, the number of flowering plants was very low (21 flowering individuals instead of 58 in non-protected plants, and 14 instead of 64 in protected plants). However, we found similar trends than in 2001, but these were not always statistically significant, probably due to the low number of replicates.

After the onset of flowering in 2002, $74.3 \%$ of all the flowering plants showed infestation by larvae of Geomyia alpina. Again, predation by gall midge larvae did not affect the number of seeds per flower head $\left(F_{1,15}=0.1, P=0.7\right)$. Seed number per flower head did not differ between slightly and heavily infested flower heads $\left(F_{1,15}=0.1, P=0.7\right)$.

In non-protected plants, total seed mass per flower head was reduced by $19.7 \%$ compared to protected plants $\left(F_{1,15}=0.9, P=0.4\right)$, and individual seed mass of heavily infested flower heads was reduced by $23.3 \%$ compared to slightly infested plants $\left(F_{1,15}=0.1, P=0.8\right)$.

Percent germination of seeds from nonprotected plants was significantly different from 


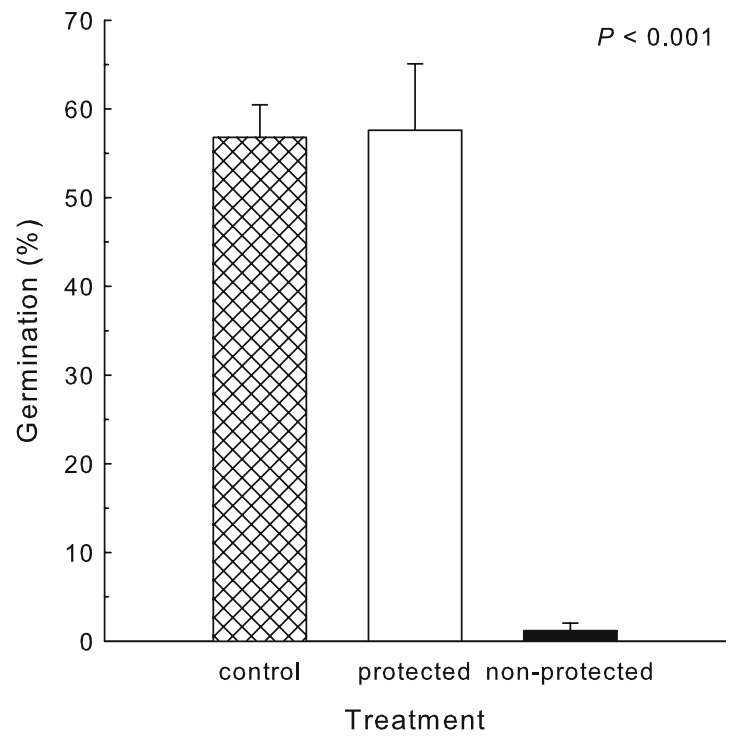

Fig. 4 Effect of pre-dispersal seed predation by gall midge larvae on percent germination (mean $\pm \mathrm{SE}$ ) of Geum reptans. Seeds originating from an uninfested population served as control

seeds from protected plants (it was reduced by $81.7 \%$, compared to seeds from protected plants; Kruskal-Wallis test; chisquare $=6.6, P<0.05$ ), while percent germination of seeds from protected plants did not differ (Kruskal-Wallis test; chisquare $=1.9, P=0.2$ ) when compared with seeds originated from an uninfested population. Simulated population growth rate decreased from $\lambda=1.055$ to $\lambda=1.042$ when viable seed number was reduced to model predation. This would result in a decrease of population size by $35.9 \%$ after 30 years, confirming results for 2001 .

\section{Discussion}

Our results demonstrate that predation by seed damaging larvae of the gall midge Geomyia alpina heavily reduced seed mass per flower head in Geum reptans and caused seeds to be mostly nonviable. Predation had no influence on the number of developing seeds per flower head. Interestingly, seed predation resulted in an increase in stolon dry-weight which may indicate a trade-off between sexual reproduction and clonal propagation. However, despite substantial reduction in viable seeds, the population growth rate $(\lambda)$ of $G$. reptans was only slightly affected by pre-dispersal seed predation suggesting that the persistence of this long-lived clonal species did not depend on current seed production alone.

Given the ubiquity of seed consuming insects often occurring at high densities and predominantly showing host-specificity, pre-dispersal seed predation provides the potential to strongly influence plant performance. In some populations of $G$. reptans seeds are subject to heavy predation by larvae of the host-specific gall midge G. alpina developing inside the flower heads and thereby sucking on the immature seeds. In the two years of the study, almost $75 \%$ of the control plants were infested by larvae indicating the high presence of these predators in the studied population. Exclusion of larvae by the use of an insecticide resulted in a significantly higher seed mass per flower head. Even more, individual seed mass decreased with increasing infestation intensity affecting heavily the viability of mature seeds and confirming that pre-dispersal seed predation directly has a negative effect on reproduction of G. reptans. Reduced reproductive output due to pre-dispersal seed predation has been well documented for a variety of species (e.g. Louda 1982; De Steven 1983; Louda and Potvin 1995; Briese 2000; Kelly and Dyer 2002; Fröborg and Eriksson 2003; Szentesi and Jermy 2003). However, contrary to most other studies concerning seed consuming insects, predation had no influence on the number of developing seeds per flower head. Since gall midge larvae used to suck sap from plant tissues (Skuhravá et al. 1984), i.e. developing ovules in case of G. reptans, their feeding behaviour explains why seed number, unlike seed mass, remained unaffected by predation.

Interestingly, flower heads with high seed numbers also had highest attack intensities. Thus, female gall midges seemed to prefer flower heads containing more seeds for oviposition, thereby maximising fitness of their off-spring. Selective oviposition on plants with higher seed numbers per flower head has been demonstrated for Polemonium foliosissimum predated by an anthomyiid fly (Zimmerman 1979, 1980). Also Molau et al. (1989) found evidence for higher predation frequencies by two lepidopterian predators in larger inflorescences of Bartsia alpina. 
Clearly, developing reproductive structures are a sink continuously requiring the supply of resources (Lee 1988), and the removal of a fraction of this sink may lead to a change in resource allocation (Hendrix 1988). Removal of seeds has been observed to result in the production of additional flowers or fruits as an effect of reduced floral abortion (Hendrix 1979; Islam and Crawley 1983; Lehtilä and Syrjänen 1995). Nevertheless, compensation in growth due to herbivory is controversially discussed (e.g. Belsky 1986; McNaughton 1986; Järemo et al. 1996; Crawley 1997). Positive responses may be associated with release of apical dominance rather than compensating directly for seed losses (Doak 1991). In G. reptans, no compensation in vegetative plant biomass due to predation by gall midge larvae occurred. Non-protected plants did not compensate for seed losses, neither by reduced abortion rates nor by production of additional flower heads or stolons. In G. reptans, because of the sucking habit of the gall midge larvae, the proportion of saved resources may be low and the short growing season does not allow the onset of additional reproductive organs. Interestingly, we found evidence for an increase of stolon dry-weight in nonprotected plants suggesting a change in resource allocation due to seed predation favouring growth of stolons and thereby possibly clonal propagation. Since the higher stolon dry-weight of nonprotected plants tended to be associated with an increase in length, this might indicate escape of predation by clonal daughter rosettes spreading away from infested mother plants. However, as leafy stolons of G. reptans may mainly support themselves, it seems unlikely that a higher stolon mass may increase clonal establishment and therefore directly compensate for reduced sexual establishment due to seed losses.

Clearly, pre-dispersal seed predation has the potential to act on the maintenance of populations if their persistence directly depends on the number of available seeds (e.g. Janzen 1971; Harper 1977; Andersen 1989; Crawley 1990, 1992; Louda and Potvin 1995; Kelly and Dyer 2002). Even episodic seed limitation occurring in 2 years out of 10 can lead to significant impacts on population level (Maron and Gardner 2000). In particular, plants with transient or no seed banks are strongly affected from seed loss caused by predation decreasing adult plant density (Louda and Potvin 1995; Maron and Gardner 2000). Remaining of gall midges at relatively constant population levels in a locality for long time periods is most common (Skuhravá et al. 1984) and $G$. reptans is not expected to form a persistent seed bank buffering potential seed losses in time (Schwienbacher and Erschbamer 2002). Immigration of seeds from other sites is considered to be very rare (Pluess and Stöcklin 2004). Our results demonstrate that seed viability of nonprotected plants was substantially reduced in two consecutive years (at least by $80 \%$ ) indicating deleterious effects of predation on germination ability of seeds. Simulation of population growth revealed a decrease in population size by $\mathrm{c}$. $36-38 \%$ after 30 years due to seed loss, but population growth rate $\lambda$ did not drop below the sustainable threshold $(\lambda=1)$. Thus, despite heavy impacts on reproduction, pre-dispersal seed predation does not limit population growth of G. reptans heavily as it has been shown for other perennial species (e.g. Andersen 1989; Fröborg and Eriksson 2003, but see Kelly and Dyer 2002). There are two possible reasons for this: Firstly, in long-lived perennials, recruitment may often be related to the availability of safe-sites rather than to seed number (Andersen 1989; Eriksson and Ehrlén 1992). Therefore, predation of even high fractions of seeds may not lower seedling recruitment (cp. Crawley 1992). However, in a demographic study of $G$. reptans (Weppler et al. 2006), we did not find evidence for a direct relationship between seed number and seedling recruitment. Thus, recruitment of seeds may be safe-site limited. Secondly, since G. reptans regularly produces above-ground stolons, clonal propagation may balance reduced sexual recruitment caused by seed predation. Matrix modelling revealed that sexual reproduction and clonal propagation similarly contributed to population dynamics in this species demonstrating even that clonal propagation alone may be sufficient to maintain population growth of $G$. reptans. Elasticity analysis showed that population growth of $G$. reptans was most sensitive to changes in adult longevity as it has been shown for many long-lived species (Silvertown et al. 1993) and 
assigning only minor importance of sexual reproduction for population dynamics.

Although, pre-dispersal seed predation by host-specific gall midge larvae did not limit population growth of $G$. reptans, the production of viable seeds was substantially reduced. Therefore, infested populations may have reduced amounts of seeds available for dispersal and successful colonisation events of new sites which may be of particular importance for a species growing in the naturally fragmented alpine landscape.

Acknowledgements We would like to thank Marcela Skuhravá who kindly determined the gall midge species. Gabrielle Schaer helped counting seeds and Pascal A. Niklaus gave valuable comments on an earlier draft of the manuscript. We are especially grateful to Michaela Ernst, I. Tanya Handa, Kai Huovinen, Armin Witzke, and Thomas Zumbrunn for field assistance. This study has been supported by the Swiss National Science Foundation, project no. 31-59271.99 and a grant from the Basler Stiftung für biologische Forschung.

\section{References}

Albrectsen BR (2000) Flowering phenology and seed predation by a tephritid fly: escape of seeds in time and space. Ecoscience 7:433-438

Andersen AN (1989) How important is seed predation to recruitment in stable populations of long-lived perennials? Oecologia 81:310-315

Belsky AJ (1986) Does herbivory benefit plants? A review of the evidence. Am Nat 127:870-892

Briese DT (2000) Impact of the Onopordum capitulum weevil Larinus latus on seed production by its hostplant. J Appl Ecol 37:238-246

Caswell H (2001) Matrix population models: construction, analysis, and interpretation. Sinauer Associates, Sunderland

Cohen D (1968) A general model of optimal reproduction in a randomly varying environment. J Ecol 56:219-228

Crawley MJ (1983) Herbivory: the dynamics of animalplant interactions. Blackwell Scientific Publications, Oxford

Crawley MJ (1990) The population dynamics of plants. Philos Trans R Soc Lond B 330:125-140

Crawley MJ (1992) Seed predators and plant population dynamics. In: Fenner M (ed) Seeds: the ecology of regeneration in plant communities. CAB International, London, pp 157-191

Crawley MJ (1997) Plant-herbivore dynamics. In: Crawley MJ (ed) Plant ecology. Blackwell Scientific Publications, Oxford, pp 401-474

De Steven D (1983) Reproductive consequences of insect seed-predation in Hamamelis virginiana. Ecology 64:89-98
Doak DF (1991) The consequences of herbivory for dwarf fireweed - different time scales, different morphological scales. Ecology 72:1397-1407

Eriksson O (1995) Asynchronous flowering reduces seed predation in the perennial forest herb Actaea spicata. Acta Oecol 16:195-203

Eriksson O (1996) Regional dynamics of plants: a review of evidence for remnant, source-sink and metapopulations. Oikos 77:248-258

Eriksson O, Ehrlén J (1992) Seed and microsite limitation of recruitment in plant populations. Oecologia 91:360-364

Fröborg H, Eriksson O (2003) Predispersal seed predation and population dynamics in the perennial understorey herb Actaea spicata. Can J Bot 81:1058-1069

Harper JL (1977) Population biology of plants. Academic Press, London

Hendrix SD (1979) Compensatory reproduction in a biennial herb following insect defloration. Oecologia 42:107-118

Hendrix SD (1988) Herbivory and its impact on plant reproduction. In: Lovett Doust J, Lovett Doust L (eds) Plant reproductive ecology. Oxford University Press, New York, pp 246-263

Heß D (2001) Die Alpenblumen: erkennen, verstehen, schützen. Eugen Ulmer, Stuttgart

Islam Z, Crawley MJ (1983) Compensation and regrowth in Ragwort (Senecio jacobaea) attacked by Cinnabar Moth (Tyria jacobaeae). J Ecol 71:829-843

Janzen DH (1971) Seed predation by animals. Annu Rev Ecol Syst 2:465-492

Järemo J, Nilsson P, Tuomi J (1996) Plant compensatory growth: herbivory or competition? Oikos 77:238-247

Kelly CA, Dyer RJ (2002) Demographic consequences of inflorescence-feeding insects for Liatris cylindracea, an iteroparous perennial. Oecologia 132:350-360

Law R, Cook RED, Manlove RJ (1983) The ecology of flower and bulbil production in Polygonum viviparum. Nord J Bot 3:559-565

Lee TD (1988) Patterns of fruit and seed production. In: Lovett Doust J, Lovett Doust L (eds) Plant reproductive ecology: patterns and strategies. Oxford University Press, New York, pp 179-202

Lehtilä K, Syrjänen K (1995) Compensatory responses of two Melampyrum species after damage. Funct Ecol 9:511-517

Leimu R, Syrjänen K, Ehrlén J, Lehtilä K (2002) Predispersal seed predation in Primula veris: amongpopulation variation in damage intensity and selection on flower number. Oecologia 133:510-516

Louda SM (1982) Limitation of the recruitment of the shrub Haplopappus squarrosus (Asteraceae) by flower- and seed-feeding insects. J Ecol 70:43-53

Louda SM, Potvin MA (1995) Effect of inflorescencefeeding insects on the demography and lifetime fitness of a native plant. Ecology 76:229-245

Mahoro S (2002) Individual flowering schedule, fruit set, and flower and seed predation in Vaccinium hirtum Thunb. (Ericaceae). Can J Bot 80:82-92 
Maron JL, Gardner SN (2000) Consumer pressure, seed versus safe-site limitation, and plant population dynamics. Oecologia 124:260-269

McNaughton SJ (1986) On plants and herbivores. Am Nat 128:765-770

Molau U, Eriksen B, Knudsen JT (1989) Predispersal seed predation in Bartsia alpina. Oecologia 81:181-185

Parker MA (1985) Size-dependent herbivore attack and the demography of an arid grassland shrub. Ecology 66:850-860

Piquot Y, Petit D, Valero M, Cuguen J, de Laguerie P, Vernet P (1998) Variation in sexual and asexual reproduction among young and old populations of the perennial macrophyte Sparganium erectum. Oikos 82:139-148

Pluess AR, Stöcklin J (2004) Population genetic diversity of the clonal plant Geum reptans (Rosaceae) in the Swiss Alps. Am J Bot 91:2013-2021

Roff DA (1974) Spatial heterogeneity and the persistence of populations. Oecologia 15:245-258

Ronsheim ML, Bever JD (2000) Genetic variation and evolutionary trade-offs for sexual and asexual reproductive modes in Allium vineale (Liliaceae). Am J Bot 87:1769-1777

Russell FL, Louda SM (2004) Phenological synchrony affects interaction strength of an exotic weevil with Platte thistle, a native host plant. Oecologia 139:525-534

Rusterholz H-P (1992) Reproduktion und klonales Wachstum von Geum reptans L. Diploma thesis. University of Basel, Basel

Rusterholz H-P, Stöcklin J, Schmid B (1993) Populationsbiologische Studien an Geum reptans L. Verh Ges Ökol 22:337-346

Schwienbacher E, Erschbamer B (2002) Longevity of seeds in a glacier foreland in the Central Alps - a burial experiment. Bull Geobot Institute ETH Zürich 68:63-71
Silvertown J, Franco M, Pisanty I, Mendoza A (1993) Comparative plant demography - relative importance of life-cycle components to the finite rate of increase in woody and herbaceous perennials. J Ecol 81:465-476

Skuhravá M, Skuhravý V, Brewer JW (1984) Biology of gall midges. In: Ananthakrishnan TN (ed) Biology of gall insects. Oxford \& IBH Publishing, New Delhi, pp 169-222

Skuhravá M, Stöcklin J, Weppler T (2006) Geomyia gen. nov. alpina sp. nov. (Diptera: Cecidomyiidae), a new gall midge species associated with flowers of Geum reptans (Rosaceae) in Switzerland. Mitteilungen der Schweizerischen Entomologischen Gesellschaft (in press)

Sutherland S, Vickery RK (1988) Trade-offs between sexual and asexual reproduction in the genus Mimulus. Oecologia 76:330-335

Szentesi A, Jermy T (2003) Pre-dispersal seed predation and seed limitation in an annual legume. Basic Appl Ecol 4:207-218

Weber HE (1995) Geum reptans. In: Conert HJ, Jäger EJ, Kadereit JW, Schultze-Motel W, Wagenitz G, Weber HE (eds) Illustrierte Flora von Mitteleuropa. Blackwell Scientific Publications, Berlin, pp 630-632

Weppler T, Stoll P, Stöcklin J (2006) The relative importance of sexual and clonal reproduction for the population growth in the long-lived alpine plant Geum reptans. J Ecol (in press)

Zimmerman M (1979) Oviposition behavior and the existence of an oviposition-deterring pheromone in $\mathrm{Hyl}$ emya (Diptera, Anthomyiidae). Environ Entomol 8:277-279

Zimmerman M (1980) Reproduction in Polemonium: predispersal seed predation. Ecology 61:502-506 